\title{
Erratum to: CIP2A is overexpressed and involved in the pathogenesis of chronic myelocytic leukemia by interacting with breakpoint cluster region-Abelson leukemia virus
}

\author{
Juandong Wang • Tao Huang • Jianzhi Sun • \\ Yuan Yu $\cdot$ Zhifang Liu $\cdot$ Wenjuan Li $\cdot$ \\ Jihui Jia $\cdot$ Chunyan Chen
}

Published online: 3 September 2014

(C) Springer Science+Business Media New York 2014

\section{Erratum to: Med Oncol (2014) 31:112 \\ DOI 10.1007/s12032-014-0112-7}

The following errors were inadvertently omitted by the author in the original publication and it has been corrected with this erratum.

1. "Inhibited the activity of PP2A, K562 cell proliferation and promoted cell apoptosis." should be replaced by "inhibited K562 cell proliferation, increased the activity of PP2A and promoted cell apoptosis" in the 19-20th line of the second column under the Abstract section on page 1 .

2. "the number of cell apoptosis was reduced after knocking down of CIP2A in K562 cells" should be replaced by "the number of apoptotic cell increased (Fig. 2e) and the rates of apoptosis also increased after

The online version of the original article can be found under doi:10.1007/s12032-014-0112-7.

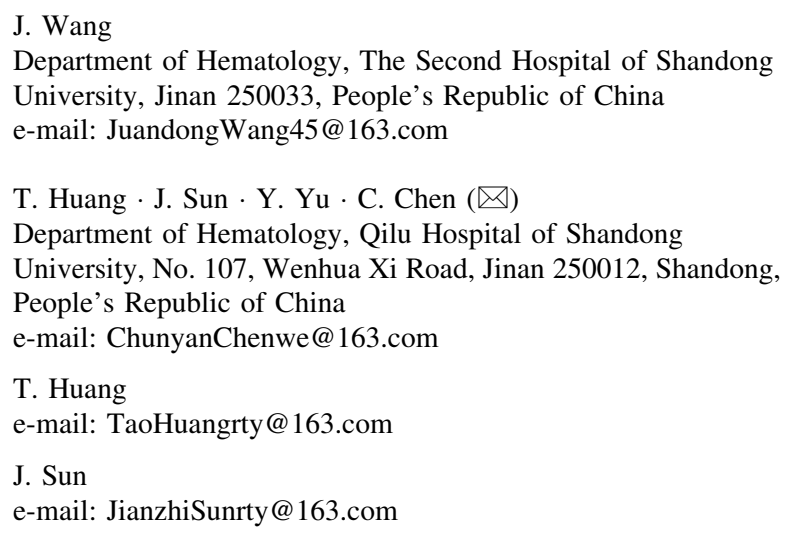

knocking down of CIP2A in K562 cells" in the 6-7th line of the first column under the Results section on page 3 .

3. " $2.67 \pm 0.15 \% \quad$ vs. $\quad 13.74 \pm 1.84 \%, \quad P<0.01$; Fig. 2e" should be replaced by "2.67 $\pm 0.15 \%$ vs. $13.74 \pm 1.84 \%, P<0.01$; Fig. $2 \mathrm{f}$ " in the 8th line of the first column under the Results section on page 3 .

4. In Fig. 2 caption, "e Apoptosis rate in cells transfected with CIP2A or control siRNA at 72-h post-transfection." should be replaced by "e The results of K562 cells apoptosis analyzed by annexin V-FITC/PI staining".

5. In Fig. 2 caption "f Apoptosis rate in cells transfected with CIP2A or control siRNA at 72-h post-transfection" should be inserted. 